\title{
Compact Dual-Band Planar Inverted-e-Shaped Antenna Using Defected Ground Structure
}

\author{
Wen Piao Lin, Dong-Hua Yang, and Zong-De Lin \\ Department of Electrical Engineering, Chang Gung University, 259 Wen-Hwa 1st Road, Kwei-Shan, Taoyuan 333, Taiwan \\ Correspondence should be addressed to Dong-Hua Yang; belldandylp@yahoo.com.tw
}

Received 11 April 2013; Revised 5 December 2013; Accepted 5 December 2013; Published 23 January 2014

Academic Editor: Alistair P. Duffy

Copyright (C) 2014 Wen Piao Lin et al. This is an open access article distributed under the Creative Commons Attribution License, which permits unrestricted use, distribution, and reproduction in any medium, provided the original work is properly cited.

This paper presents a novel dual-band planar inverted-e-shaped antenna (PIEA) using defected ground structure (DGS) for Bluetooth and wireless local area network (WLAN) applications. The PIEA can reduce electromagnetic interferences (EMIs) and it is constructed on a compact printed circuit board (PCB) size of $10 \times 5 \times 4 \mathrm{~mm}^{3}$. Experimental results indicate that the antenna with a compact meandered slit can improve the operating impedance matching and bandwidths at 2.4 and $5.5 \mathrm{GHz}$. The measured power gains at 2.4 and $5.5 \mathrm{GHz}$ band are 1.99 and $3.71 \mathrm{dBi}$; antenna efficiencies are about $49.33 \%$ and $55.23 \%$, respectively. Finally, the good performances of the proposed antenna can highly promote for mobile device applications.

\section{Introduction}

In recent years, wireless local area networks (WLANs) have tremendously advanced. The WLAN facilitates the wireless connection between laptop computers, mobile devices, and other equipment within a local area. Small volume antennas are highly attractive for Bluetooth and wireless local area network (WLAN)/worldwide interoperability mobile access (WiMAX) applications [1-4]. Additionally, the frequency bands located around $2.4 \mathrm{GHz}$ and $5 \mathrm{GHz}$ have been widely used in Bluetooth and WLAN/WiMAX simultaneously. A multiband antenna is thus more efficient than multiple antennas specifically designed to operate on each frequency band.

Dual-band antennas, composed of a pair of dipoles or of a T-shaped monopole, have been presented to cover the frequency band of 2.4 and $5 \mathrm{GHz}$ in $[5,6]$. According to [715], the meander slit antenna includes many basic folded elements in various patterns and it can produce various resonant frequencies markedly lower than resonances frequency of a single-element antenna under the same length. Apparently, owing to the various current cancellation and reinforcements, a larger number of higher resonances frequencies can occur on a meander monopole antenna than on a simple monopole of the same length [7-11]. The antenna with a meandered slit can reduce the tag sizes. Moreover, meandered slit can use open-end slots in the ground plane, generally located under the radiating patch. The size reduction method is highly promising for implementing practical antenna. Previous work [12-15] described the feasibility of using a slotted ground plane for broadening the operational bandwidth of a small terminal antenna.

Additionally, due to their small size, the planar inverted$\mathrm{F}$ antennas (PIFAs) or monopole antennas have a narrow bandwidth, especially at $5 \mathrm{GHz}$ band. Numerous dual-band designs have been developed for WLAN and Bluetooth applications [16, 17]. Our previous studies have established that dual-band F-shaped monopole antennas are characterized by a simple geometrical structure that assures a small volume, a low cost, and a simple integration on a circuit board, as required by the modern handset terminals $[18,19]$. Recent studies have also demonstrated the effectiveness of the WLAN antennas using an inverted-F strip integrated on the circuit board of a communication device in further reducing the antenna volume and decreasing the fabrication cost. Therefore, owing to its sufficient bandwidth, radiation efficiency, power gain, and electrostatic discharge (ESD) protection, the PIFA is highly attractive for WLAN applications [20]. 


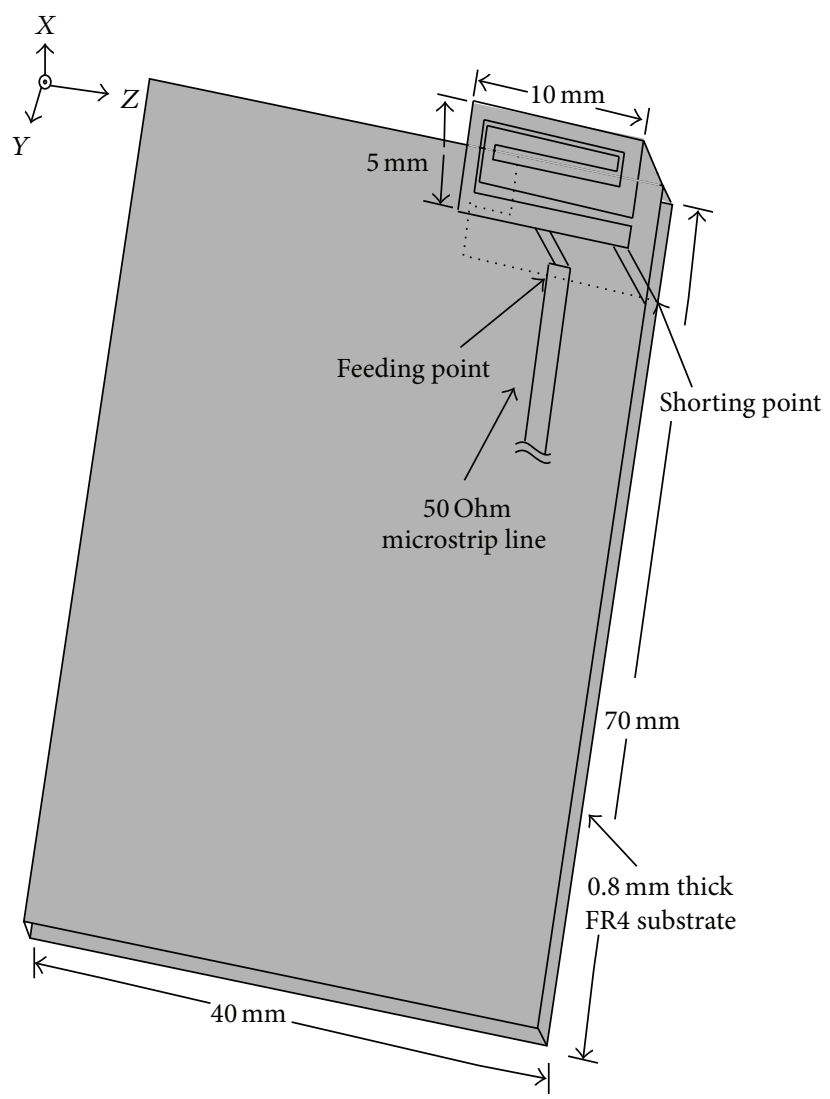

FIGURE 1: Proposed dual-band meander inverted-e-shaped antenna.

This work presents a planar inverted-e-shaped antenna (PIEA) based on a flaw earth structure to increase the bandwidth of PIFA. The shape of the antenna resembles that of the inverted alphabet e, explaining why the antenna is referred to as an e antenna. The radiating part is shorted with the ground plane to reduce the antenna size. Moreover, with its satisfactory gain, the proposed PIEA can be accommodated in small card shaped areas for different compact wireless systems. The proposed antenna can also be considered as a miniaturized and low-cost antenna model, applicable for many small wireless systems requiring an omnidirectional radiation pattern.

\section{Antenna Design}

Figure 1 shows the configuration of proposed dual-band inverted-e-shaped antenna. All of the electromagnetic analyses have been performed using a software package of Ansoft high frequency structure simulator (HFSS), based on the three-dimensional finite element method (3D FEM). The size of a ground plane is $70 \times 40 \mathrm{~mm}^{2}$ considered as the printed circuit board (PCB) of a practical handset, and the metal is only printed on the front surface of an FR-4 substrate with relative permittivity 4.6 and height of $0.8 \mathrm{~mm}$. The antenna has a compact size of $10 \times 5 \times 4 \mathrm{~mm}^{3}$. Figure 2 shows the geometrical configuration with the designed shapes of $\mathrm{L}, \mathrm{U}$, and e. Figures 2(a), 2(b), and 2(c) show the top view of the designed antenna size, where $W_{1}=10 \mathrm{~mm}, W_{2}=9 \mathrm{~mm}, W_{3}=$ $7.75 \mathrm{~mm}, W_{4}=7.15 \mathrm{~mm}, L_{1}=5 \mathrm{~mm}, L_{2}=3.5 \mathrm{~mm}, L_{3}=2.5 \mathrm{~mm}$, $L_{4}=0.65 \mathrm{~mm}, S_{1}=0.5 \mathrm{~mm}, S_{2}=0.25 \mathrm{~mm}, S_{3}=0.25 \mathrm{~mm}, S_{4}$ $=0.25 \mathrm{~mm}$, and $S_{5}=0.7 \mathrm{~mm}$. In addition, the meander slit eshaped structure can obtain the resonance at 2.4 and $5.8 \mathrm{GHz}$ in the small area. The structure causes the cancellation of the current due to the length of the proposed antenna longer than the quarter free-space wavelengths $(31.25 \mathrm{~mm})$ at $2.4 \mathrm{GHz}$, which results the total length is $41 \mathrm{~mm}$. According to the side view of the designed antenna shown in Figure 2(d), the distance of $D$ between the feeding point and the shorting point is $4.5 \mathrm{~mm}$, while the distance between the ground plane and the radiating structure is $4 \mathrm{~mm}$.

The conventional meandered slit antenna produces a wire configuration presenting capacitive and inductive reactance effects, which mutually cancel out each other. Resonance frequencies are therefore produced at markedly lower frequencies than those in the case of straight wire antenna of the same height at the expense of a narrow bandwidth and low gain, especially when the antenna must be arranged in a surface of few square centimeters. The proposed planar inverted-e-shaped antenna (PIEA) uses a meander slit with a DGS, in which an "e" folding of the meandered slit confers to the radiating structure which differs from that of a conventional straight dipole of the same length. Moreover, the lowest resonant frequency can be tuned using the same tuning elements. 


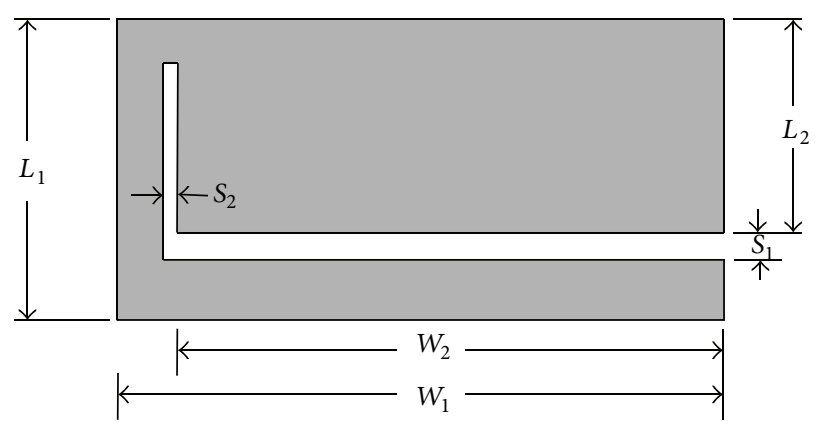

(a)

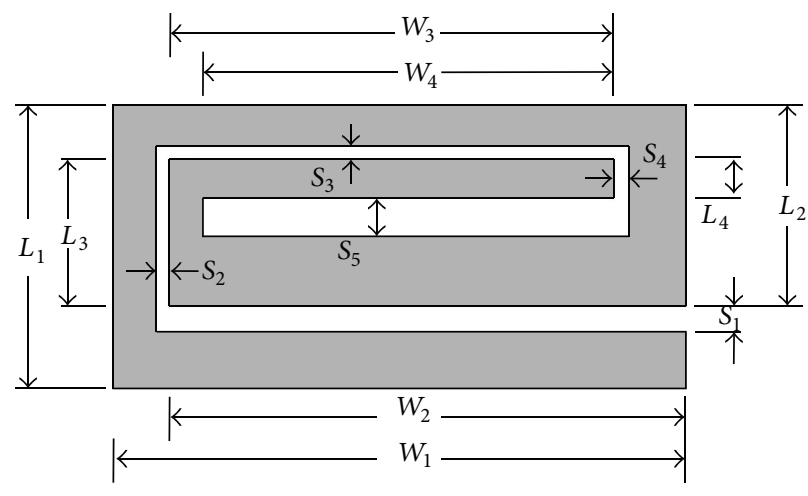

(c)

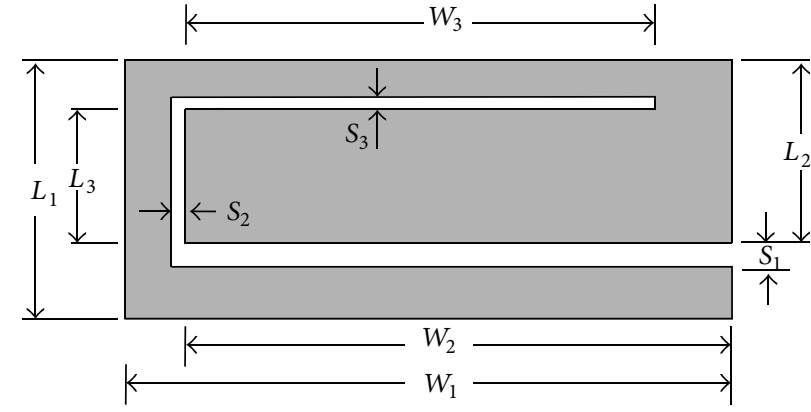

(b)

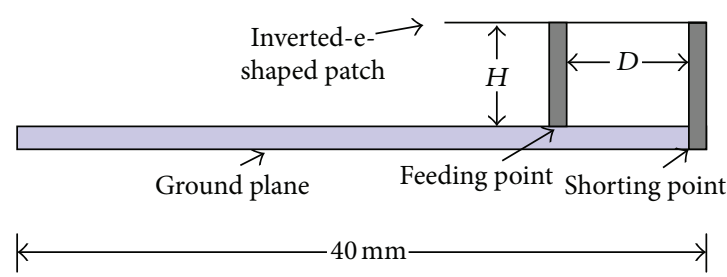

(d)

Figure 2: The geometry of designed ((a), (b), and (c)) top view and (b) side view of planar inverted-e antenna.

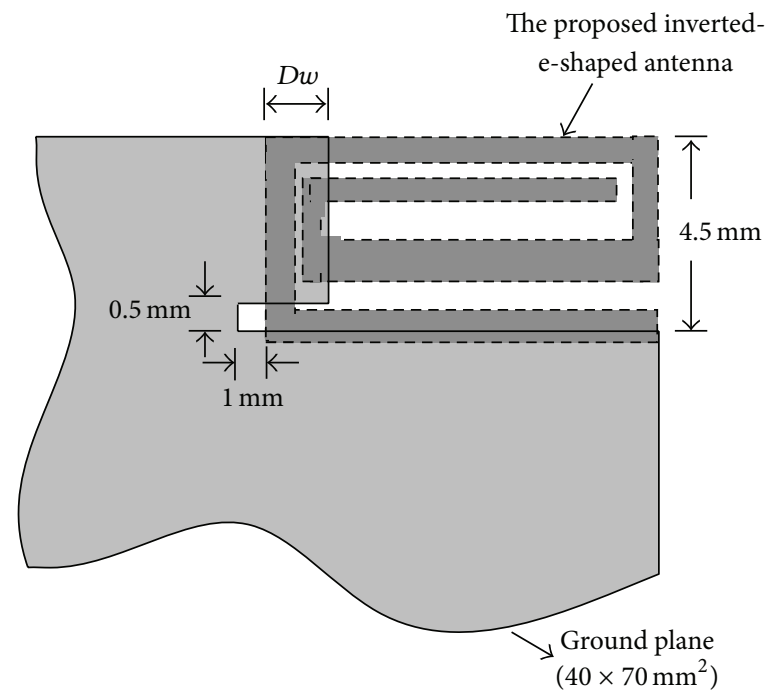

FIGURE 3: The geometry of the designed top view of proposed DGS.

As mentioned earlier, the proposed antenna consists of an inverted-e-shaped meander slit with a rectangular DGS. Figure 3 schematically depicts the proposed DGS. A previous work [12-15] has shown that the size and shape of the chassis could play a significant role in broadening the bandwidth of a terminal antenna. This means that slits in a ground plane could facilitate efforts to optimize the bandwidth of the antenna.

Figure 4 shows the simulation S-parameters for the various antenna shapes of $\mathrm{L}, \mathrm{U}$, and e. It is clearly observable that the return loss is changed for three designs. In the Ushaped structure, slit is added to lengthen the path of the average current for the resonance frequency at 3 and $7.4 \mathrm{GHz}$. In the e-shaped structure, the small area can obtain the resonance at 2.4 and $5.99 \mathrm{GHz}$.

The simulated real and imaginary impedance of proposed PIEA without DGS in the ground plane are shown in Figures 5(a) and 5(b). In order to change the resonant frequencies, we adjust the capacitor and inductor parameters, in the antenna circuit. Moreover, the real and imaginary 


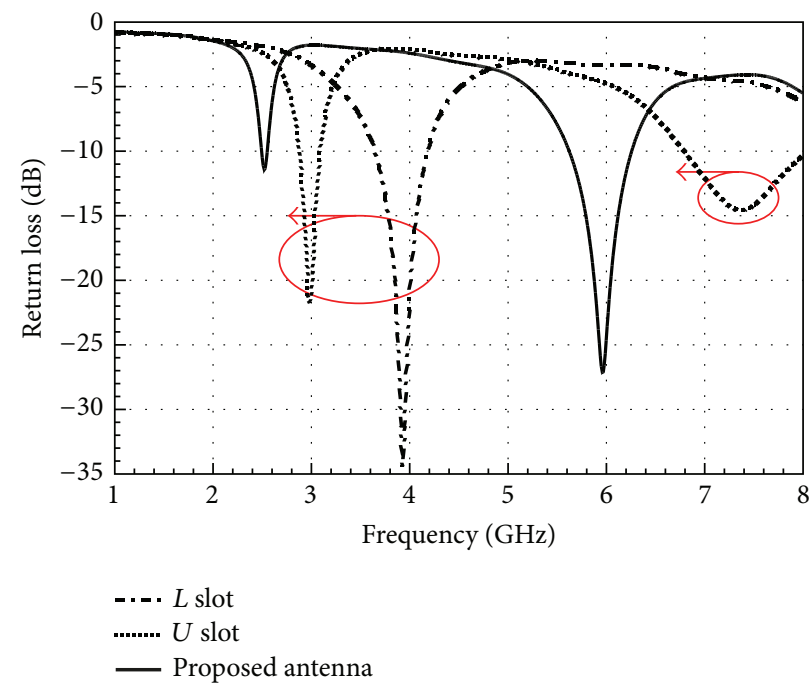

Figure 4: The simulation return losses results for the proposed L, U, and e-shaped slit S-parameter.

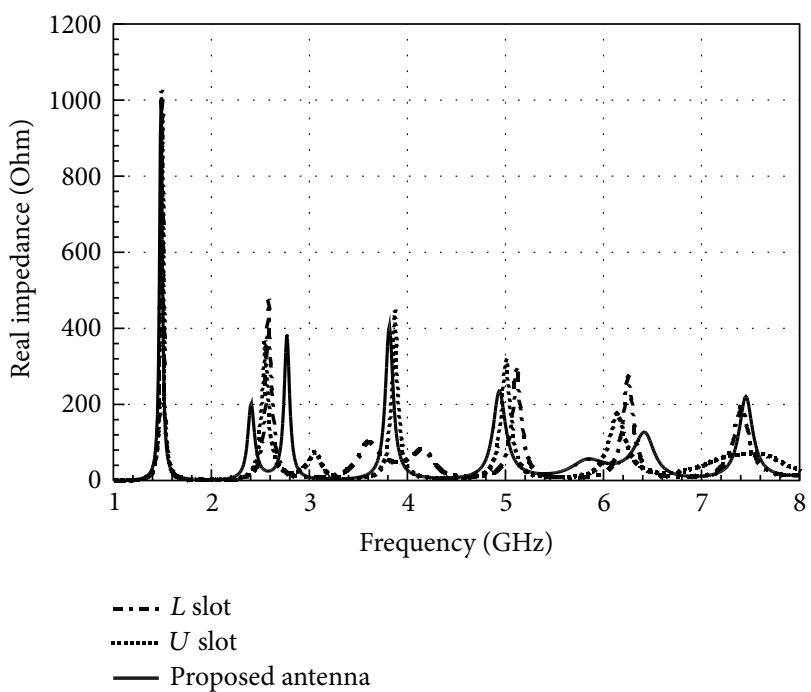

(a)

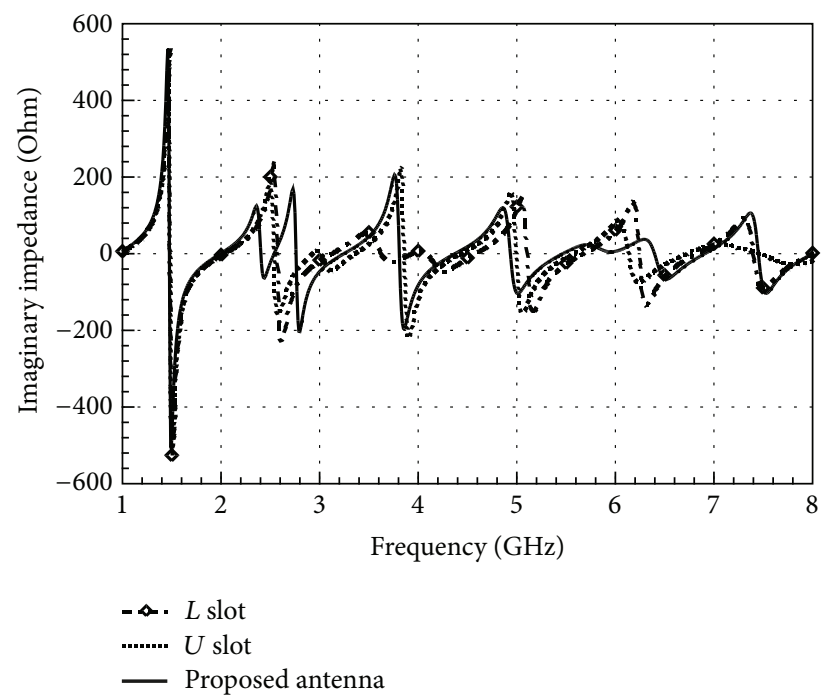

(b)

FIGURE 5: Simulation results of proposed slit shaped (a) real and (b) imaginary impedance.

impedance part of its admittance are approximately 50 and $0 \mathrm{Ohm}$, respectively, according to simulation results.

The simulated results of the antenna are shown in Figure 6 by the tuned parameters of D in Figure 2(d) and Dw in Figure 3, respectively. From Figure 6(a), we can see that the optimal distance of $\mathrm{D}$ is $4.5 \mathrm{~mm}$ to obtain the better impedance matching. Moreover, the better bandwidth can be achieved to adjust the distance of Dw at $1.5 \mathrm{~mm}$ as shown in Figure 6(b).

Figure 7 shows the simulated reflection coefficient $S_{11}$ of proposed PIEA without DGS and with DGS in the ground plane. According to this figure, the proposed antenna without DGS presents two resonant peaks (see dotted line in Figure 7). In particular, the first peak appears at about $2.45 \mathrm{GHz}$ with a return loss of $-11 \mathrm{~dB}$, while the second peak appears at $5.99 \mathrm{GHz}$ where a return loss of about $-27 \mathrm{~dB}$ is found. From Figure 7 it appears that a bandwidth of $0.63 \mathrm{GHz}$ $(5.6-6.23 \mathrm{GHz})$ is obtained only in the neighborhood of $5.99 \mathrm{GHz}$. A different frequency behavior is observed for the radiating structure equipped with DGS. In fact, in this case the two peaks in the curve of the return loss (solid line in Figure 7) are equal to about $-14.9 \mathrm{~dB}$ at $2.4 \mathrm{GHz}$ and about $-18.2 \mathrm{~dB}$ at $5.62 \mathrm{GHz}$, respectively. The bandwidths of these frequencies are approximately $0.06(2.39-2.45)$ and $0.9(5.22-$ 6.12) $\mathrm{GHz}$, respectively. Numerical results indicate a fairly good impedance matching of the proposed PIEA with DGS, excellent broadband characteristics, and enhanced resonant performances. 


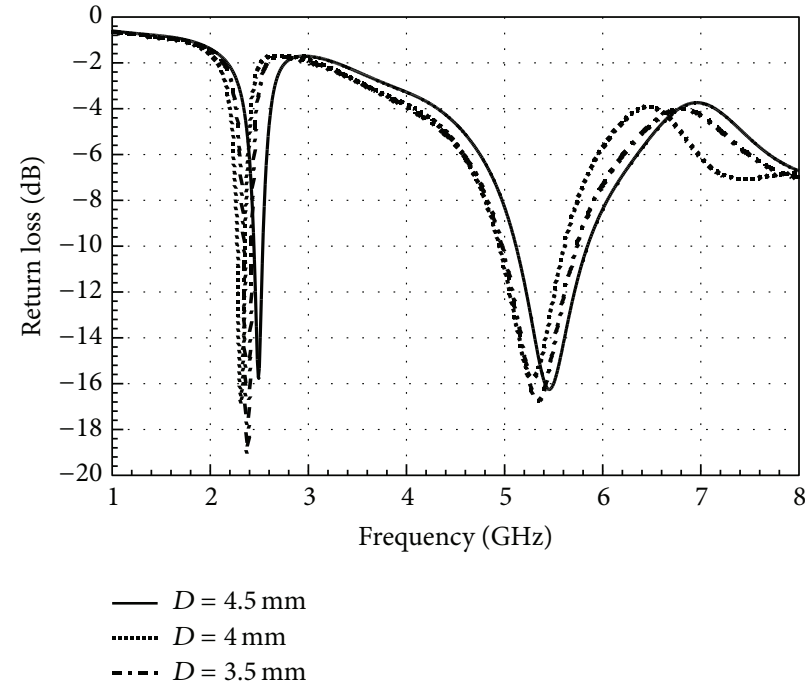

(a)

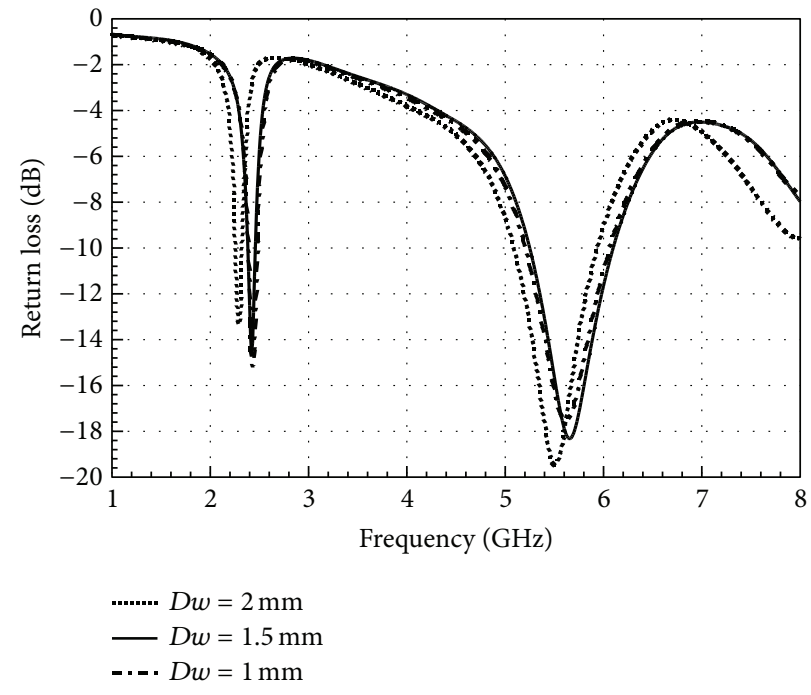

(b)

FIGURE 6: Simulation results by tuned parameters to the distance between (a) feeding and shorting plate. (b) DGS and inverted-e-shaped edge.

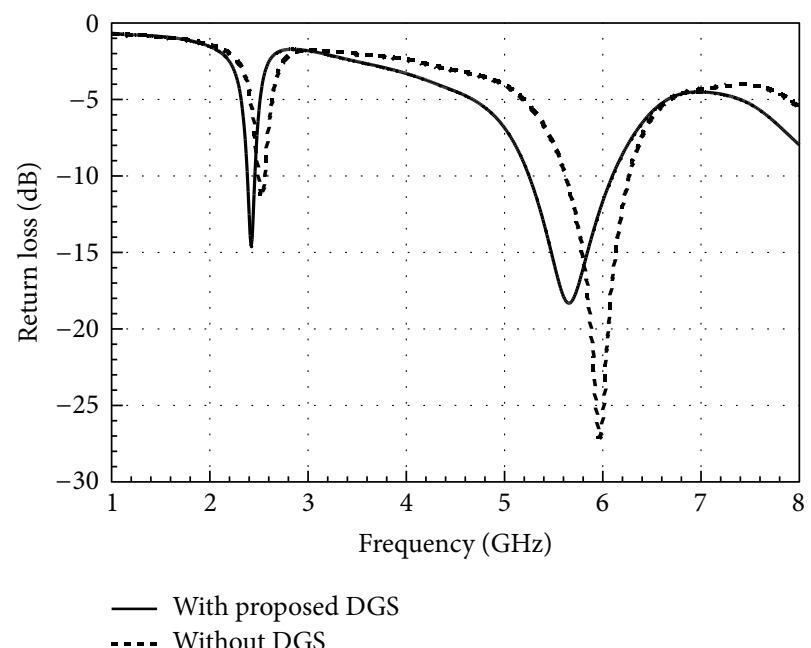

FIGURE 7: The simulated return losses $S_{11}$ for the proposed PIEA with DGS and without DGS in the ground plane.

\section{Results and Discussion}

To demonstrate the performances of the proposed PIEA, a prototype antenna which is performed by numerical simulation has been realized as shown in Figure 8. Constructed on a FR4 substrate having $\varepsilon=4.6$ and height $=0.8 \mathrm{~mm}$, the fabricated antenna was measured in 3D anechoic chamber using the Agilent E5071C Network Analyzer. Figure 9 shows the simulated and measured reflection coefficients $S_{11}$. The measured bandwidths at return loss of $-10 \mathrm{~dB}$ are 83 and $675 \mathrm{MHz}$ at the center frequency of 2.44 and $5.5 \mathrm{GHz}$, respectively. This figure reveals that the measured reflection coefficient of $S_{11}$ is rather close to the simulation results of $S_{11}$. Above results indicate that the antenna is well matched to $50 \Omega$ presenting bandwidths that are adequate for applications working at 2.4 and $5.5 \mathrm{GHz}$.

Figures 10(a) and 10(b) display the surface current distributions of the proposed antenna at the working frequency of 2.4 and $5.5 \mathrm{GHz}$, respectively. Figure 10 indicates that a stronger current distribution in an inverted-e-shaped stub than any other area implies, for the antenna impedance matching, a closer relation of the voltage to the current at the input to the antenna.

Figure 11 shows the measured $2 \mathrm{D}$ radiation power patterns in the $X-Z$ and $X-Y$ plane at 2.402, 2.441, 2.45, 2.48 , and $5.5 \mathrm{GHz}$ band. The proposed antenna has an almost monopole-like of radiation pattern in the $X-Z$ (crosspolarization) and $X-Y$ (co- and cross-polarization) plane 


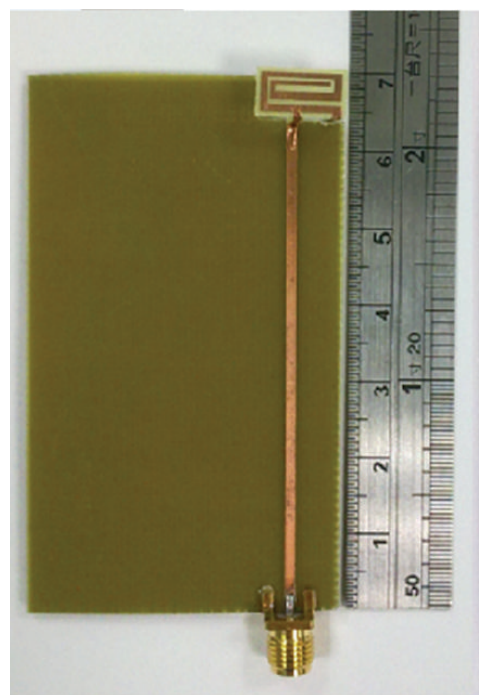

(a)

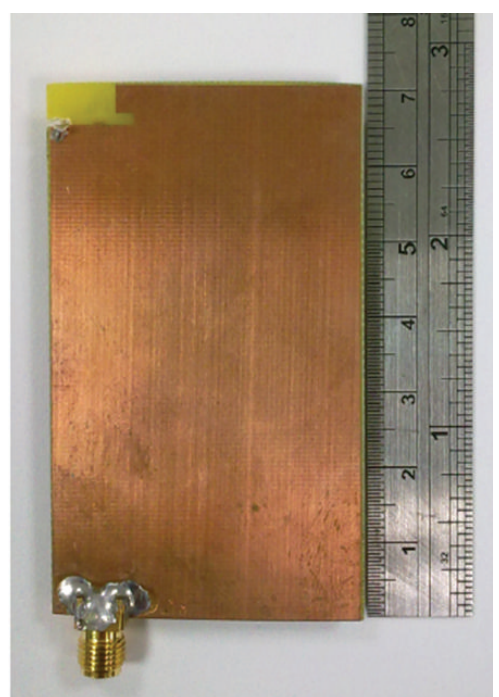

(b)

FIGURE 8: Numerical simulation and experimental measurement return losses for the proposed PIEA with DGS.

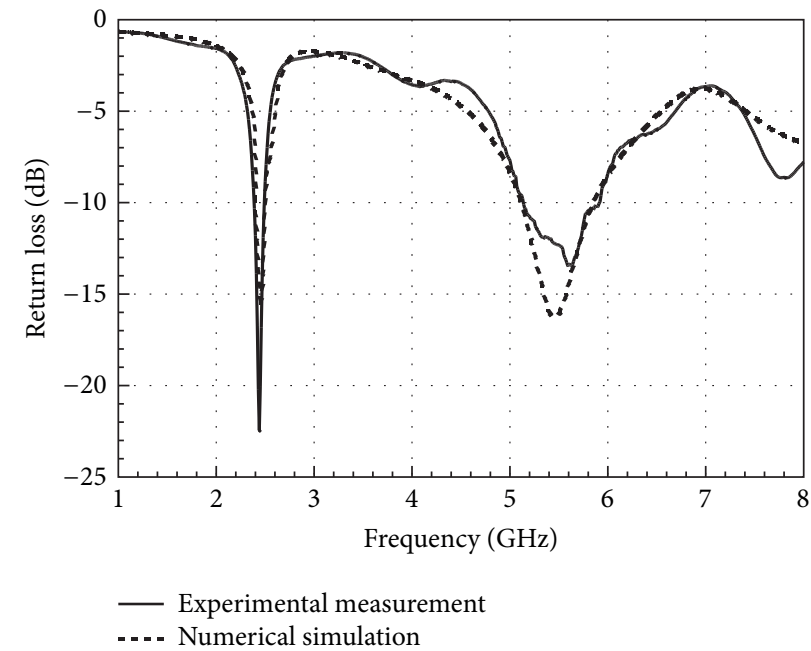

FIGURE 9: Photograph of the fabricated planar inverted-e-shaped antenna with DGS.

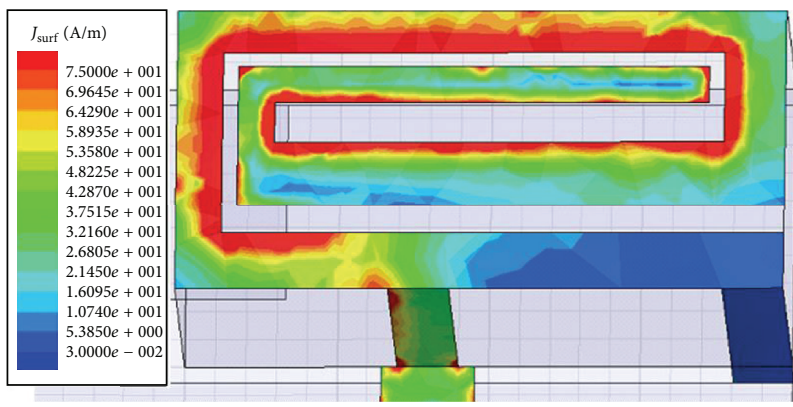

(a)

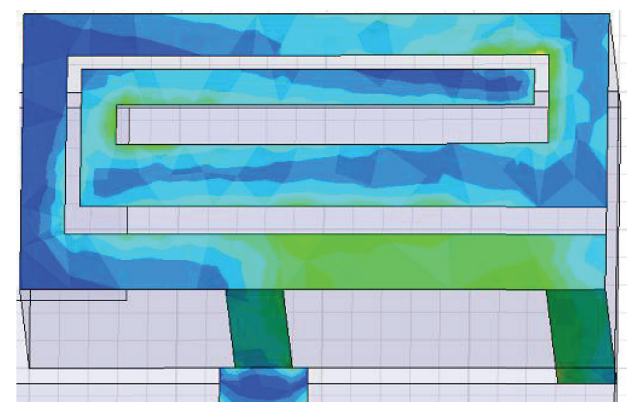

(b)

FIGURE 10: Current distributions at (a) $2.4 \mathrm{GHz}$ and (b) $5.5 \mathrm{GHz}$. 


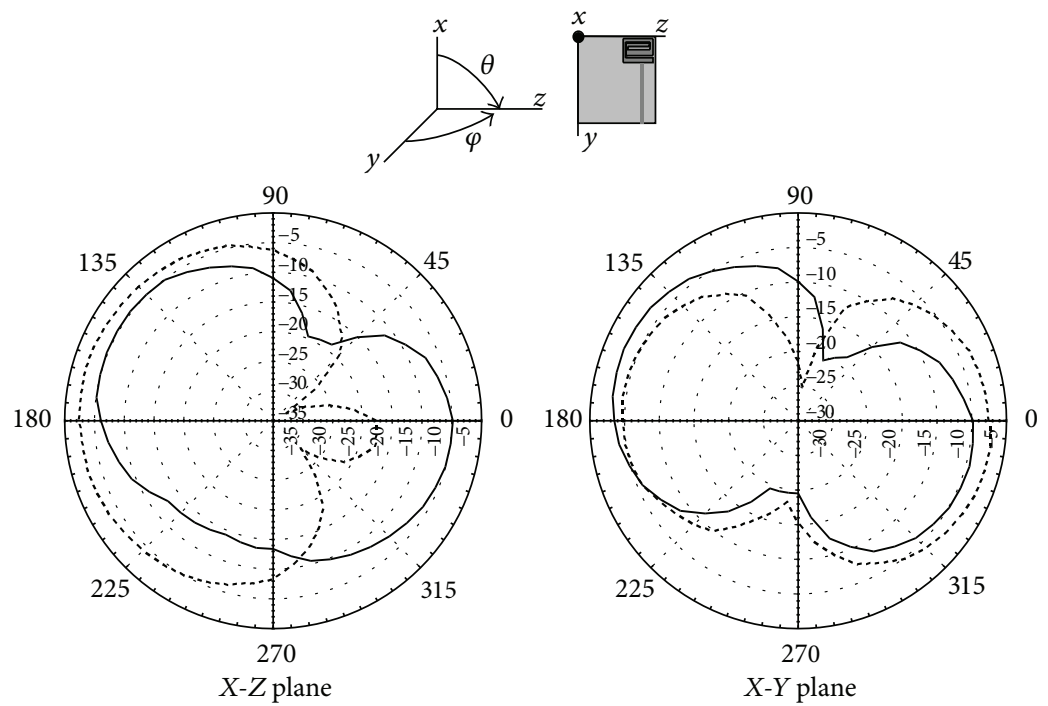

(a) At $2.402 \mathrm{GHz}$

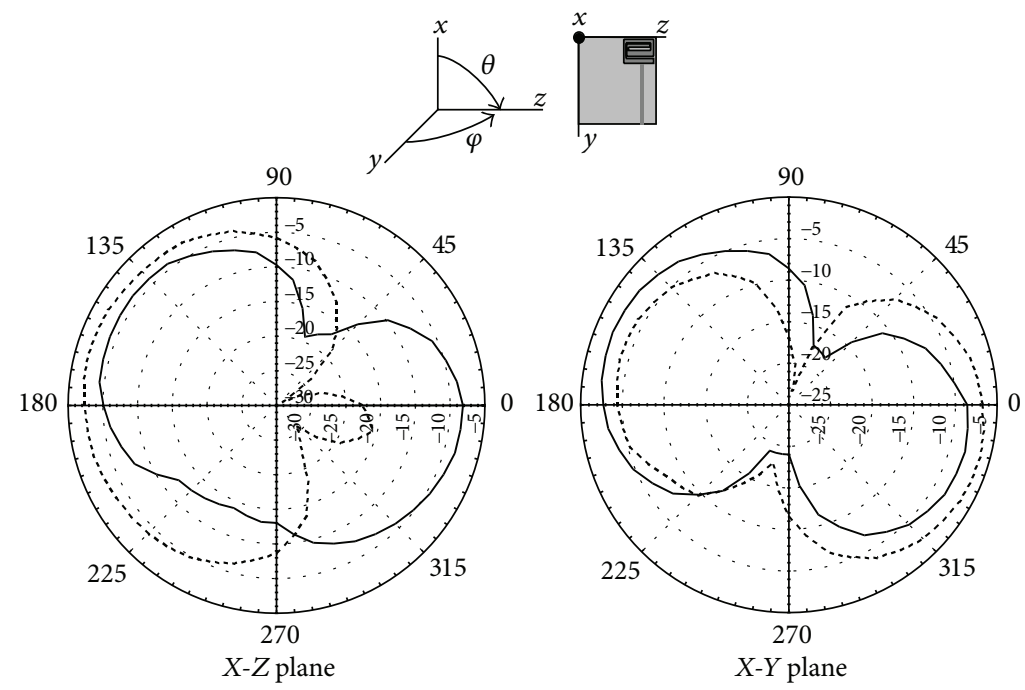

(b) At $2.441 \mathrm{GHz}$

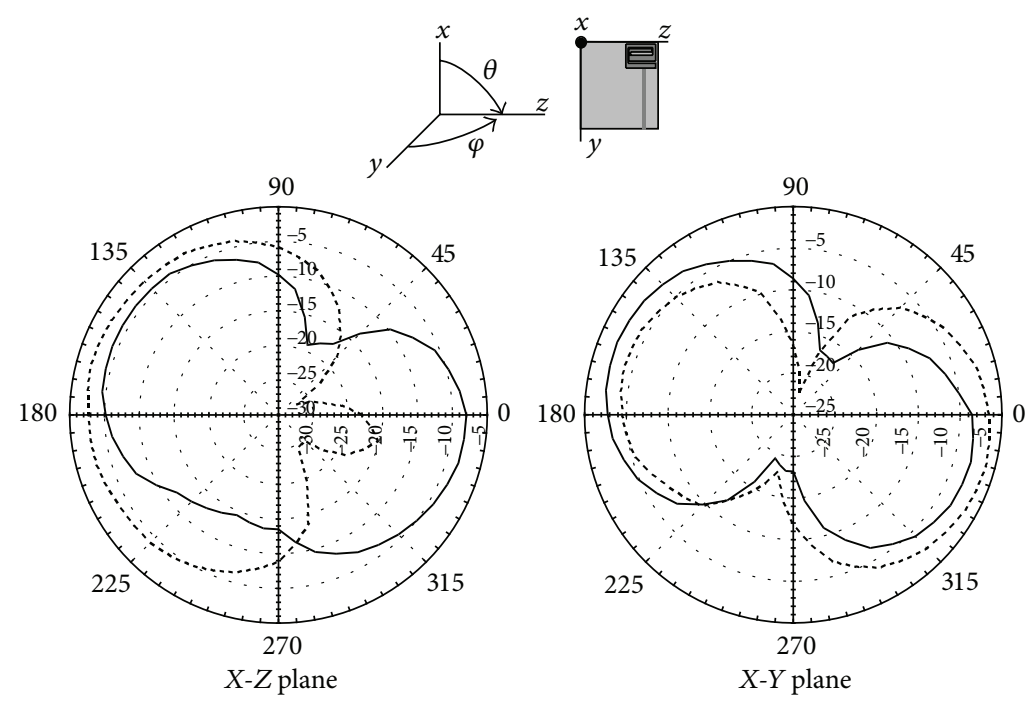

(c) At $2.45 \mathrm{GHz}$

FIgURE 11: Continued. 


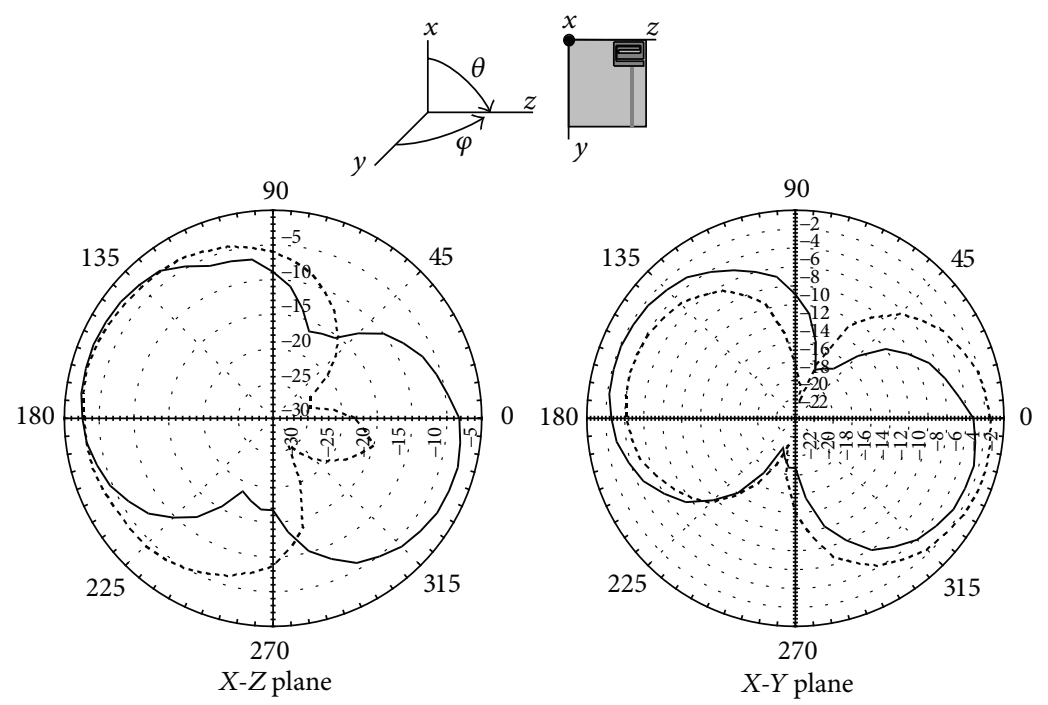

(d) At $2.48 \mathrm{GHz}$

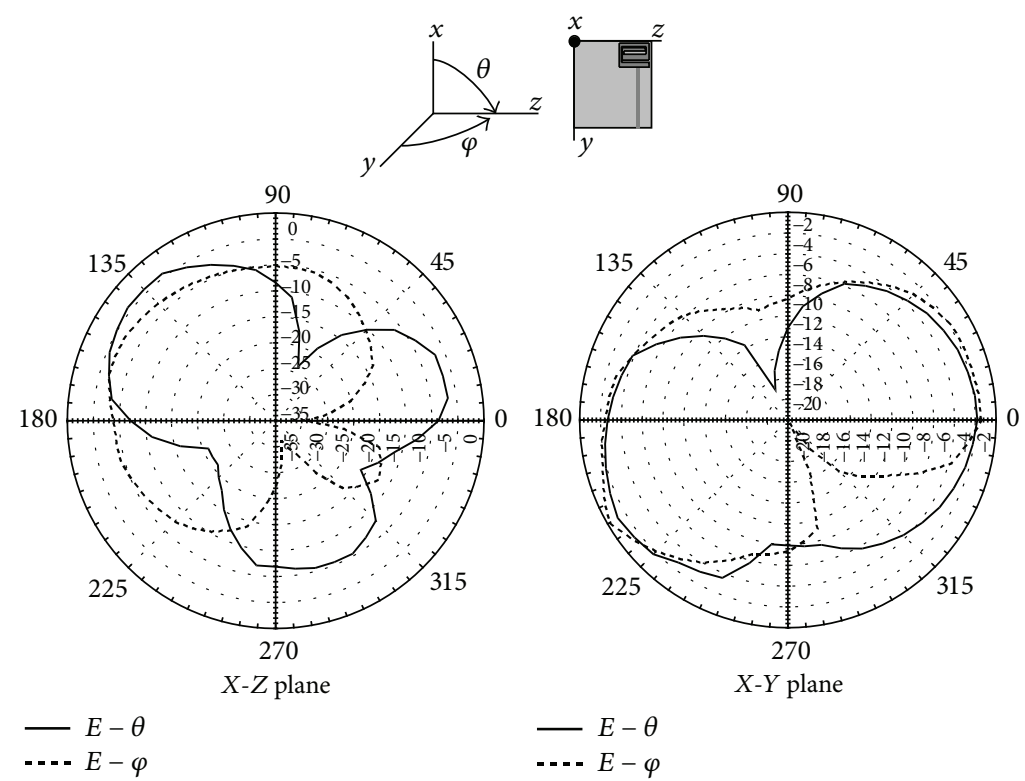

(e) At $5.5 \mathrm{GHz}$

FIGURE 11: The measured 2D radiation patterns of the proposed antenna.

due to the meander slit of a full-wavelength radiator. The antenna also exhibits a better directivity radiation power gain pattern at $X-Z$ (copolarization) plane. Our proposed antenna is an asymmetric architecture from the current distributions shown in Figure 10(a). The reference direction is along the direction of maximum current in the radiating structure and a stronger radiation pattern can produce on the copolarization. The obtained radiation patterns are near omnidirectional in $X-Z$ plane, and the radiation patterns exhibit monopole-like patterns in the $X-Y$ plane. Above experimental results indicate that the maximum antenna power gains at 2.4 and $5.5 \mathrm{GHz}$ band are 1.99 and $3.71 \mathrm{dBi}$; in addition, antenna efficiencies are 49.33 and $55.23 \%$, respectively. Measurement results demonstrate that the radiation characteristics of the proposed antenna at the operating frequencies of 2.4 and $5.5 \mathrm{GHz}$ are quite stable. The measured peak gain and antenna efficiency for the e-shaped antenna are plotted in Figure 12. The peak gain is about $2 \sim 2.2 \mathrm{dBi}$ for the lower band and $0.9 \sim 3.7 \mathrm{dBi}$ for the upper band. The antenna efficiency is about $40 \%$ for the lower band and $40 \sim 55 \%$ for the upper band. In general, the measured radiation patterns of horizontally polarized omnidirectional cover complementary space regions. Therefore, the proposed antenna can provide pattern diversity in a wireless communication system. The proposed antenna can satisfy the required specifications of fixed and mobile devices. 


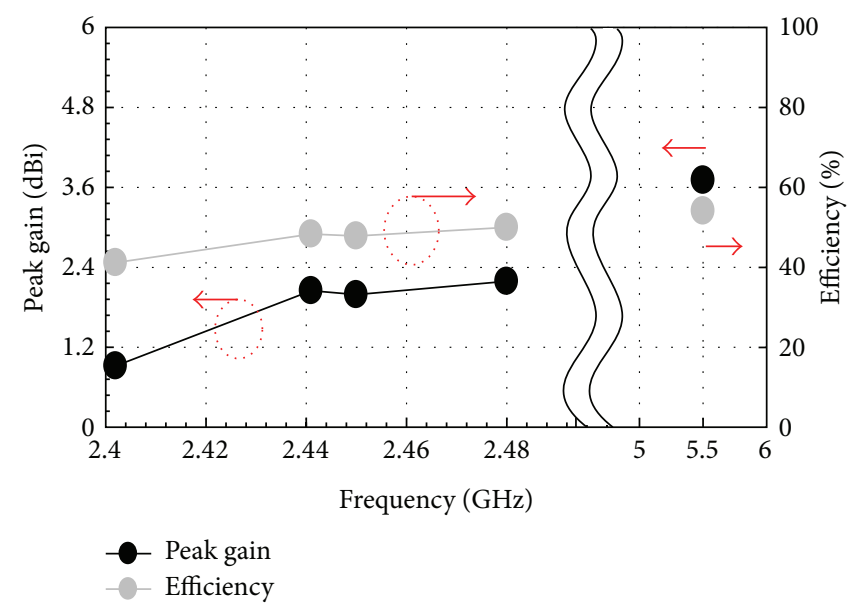

FIGURE 12: The simulated peak gain and efficiency for proposed antenna.

\section{Conclusion}

A novel planar compact meander inverted-e-shaped antenna with a DGS size of $10 \times 5 \times 4 \mathrm{~mm}^{3}$ in the ground plane has been presented. The proposed antenna with DGS can enhance the antenna performance in terms of its suppressed broadened impedance bandwidth. The measured antenna efficiencies at 2.4 and $5.5 \mathrm{GHz}$ are about 49.33 and $55.23 \%$, respectively. Additionally, experimental results correlate well with the simulation results. Moreover, desired characteristics such as excellent radiation patterns, moderate antenna gain, and low cost make the proposed antenna highly promising for Bluetooth and WLAN/WiMAX applications.

\section{Conflict of Interests}

The authors declare that there is no conflict of interests regarding the publication of this paper.

\section{Acknowledgments}

The authors wish to thank the Arima Communications Corp. for providing the test equipments and anechoic chamber and the technicians of the company for their valued suggestions useful to complete this study. The authors wish also to thank the support of the National Science Council under Contract no. NSC 99-2632-E-182-001-MY3 and the partial support received by the Chiang Education Foundation of Taipei, Taiwan. The support of the High Speed Intelligent Communication (HSIC) Research Center of the Chang Gung University, Taoyuan, Taiwan, has been also appreciated.

\section{References}

[1] X. Cai, A. Wang, and S. Gao, "A compact gourd-shaped dualband antenna for WiMAX/WLAN applications," in Proceedings of the 9th International Symposium on Antennas Propagation and EM Theory (ISAPE '10), pp. 75-78, Guangzhou, China, December 2010.
[2] P. Ciais, R. Staraj, G. Kossiavas, and C. Luxey, "Compact internal multiband antenna for mobile phone and WLAN standards," Electronics Letters, vol. 40, no. 15, pp. 920-921, 2004.

[3] H.-W. Hsieh, Y.-C. Lee, K.-K. Tiong, and J.-S. Sun, "Design of a multiband antenna for mobile handset operations," IEEE Antennas and Wireless Propagation Letters, vol. 8, pp. 200-203, 2009.

[4] Y.-S. Shin and S.-O. Park, "A compact loop type antenna for Bluetooth, S-DMB, Wibro, WiMax, and WLAN applications," IEEE Antennas and Wireless Propagation Letters, vol. 6, pp. 320323, 2007.

[5] X. -L. Quan, R. Li, Y. -H. Cui, and M. M. Tentzeris, "Analysis and design of a compact dual-band directional antenna," IEEE Antennas and Wireless Propagation Letters, vol. 11, pp. 547-5550, 2012.

[6] T. N. Chang and J.-H. Jiang, "Meandered T-shaped monopole antenna," IEEE Transactions on Antennas and Propagation, vol. 57, no. 12, pp. 3976-3978, 2009.

[7] H.-D. Chen, J.-S. Chen, and Y.-T. Cheng, "Modified invertedL monopole antenna for 2.4/5 GHZ dual-band operations," Electronics Letters, vol. 39, no. 22, pp. 1567-1569, 2003.

[8] Y. -F. Weng, S. -W. Cheung, and T. -I. Yuk, "Design of multiple band-notch using meander lines for compact ultra-wide band antennas," IET Microwaves Antennas and Propagation, vol. 6, no. 8, pp. 908-9914, 2012.

[9] F. Shen, Y. Wei, X. Xu et al., "Symmetric double V-shaped microstrip meander-line slow-wave structure for W-band traveling-wave tube," IEEE Transactions on Electron Devices, vol. 59, no. 5, pp. 1551-1557, 2012.

[10] C. Di Nallo and A. Faraone, "Multiband internal antenna for mobile phones," Electronics Letters, vol. 41, no. 9, pp. 514-515, 2005.

[11] M. Ali, G. J. Hayes, H.-S. Hwang, and R. A. Sadler, "Design of a multiband internal antenna for third generation mobile phone handsets," IEEE Transactions on Antennas and Propagation, vol. 51, no. 7, pp. 1452-1461, 2003.

[12] Y. X. Guo, K. M. Luk, K. F. Lee, and Y. L. Chow, "Double U-slot rectangular patch antenna," Electronics Letters, vol. 34, no. 19, pp. 1805-1806, 1998.

[13] T.-H. Kim and D.-C. Park, "Compact dual-band antenna with double L-slits for WLAN operations," IEEE Antennas and Wireless Propagation Letters, vol. 4, no. 1, pp. 249-252, 2005. 
[14] O. O. Olaode, W. D. Palmer, and W. T. Joines, "Effects of meandering on dipole antenna resonant frequency," IEEE Antennas and Wireless Propagation Letters, vol. 11, pp. 122-125, 2012.

[15] C.-I. Lin and K.-L. Wong, "Printed monopole slot antenna for internal multiband mobile phone antenna," IEEE Transactions on Antennas and Propagation, vol. 55, no. 12, pp. 3690-3697, 2007.

[16] Y.-M. Chen, S.-F. Chang, C.-L. Wei, Y.-T. Wang, and C.-H. Huang, "Packaged ultra-wide-band bandpass filter based on inverted-T multiple-mode resonators and inverted-F impedance transformers: TC contests," IEEE Microwave Magazine, vol. 11, no. 1, pp. 126-129, 2010.

[17] G. H. Huff and J. J. McDonald, "A spherical inverted-F antenna (SIFA)," IEEE Antennas and Wireless Propagation Letters, vol. 8, pp. 649-652, 2009.

[18] D.-B. Lin, I.-T. Tang, M.-Z. Hong, and H.-P. Lin, "A compact quad-band PIFA by using defected ground structure," in Proceedings of the IEEE Antennas and Propagation Society International Symposium (AP-S '07), pp. 4677-4680, Honolulu, Hawaii, USA, June 2007.

[19] C.-S. Kim, J.-S. Park, D. Ahn, and J.-B. Lim, "A novel 1-D periodic defected ground structure for planar circuits," IEEE Microwave and Wireless Components Letters, vol. 10, no. 4, pp. 131-133, 2000.

[20] A. Babar, L. Ukkonen, M. Soini, and L. Sydanheimo, "Planar inverted miniaturized E antenna, for compact wireless systems," in Proceedings of the IEEE International Symposium on Antennas and Propagation and USNC/URSI National Radio Science Meeting (APSURSI '09), pp. 1-4, Charleston, SC, USA, June 2009. 

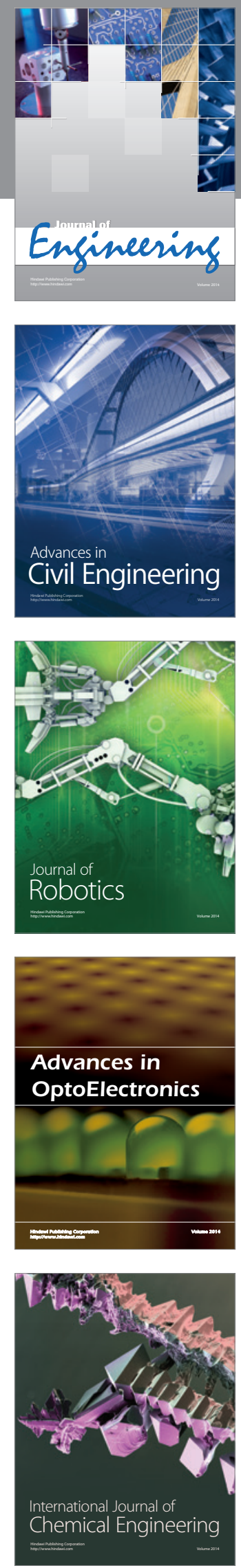

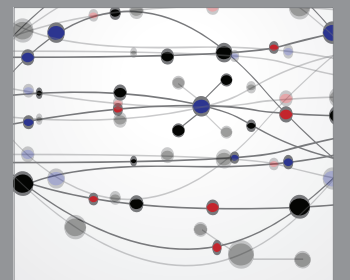

The Scientific World Journal
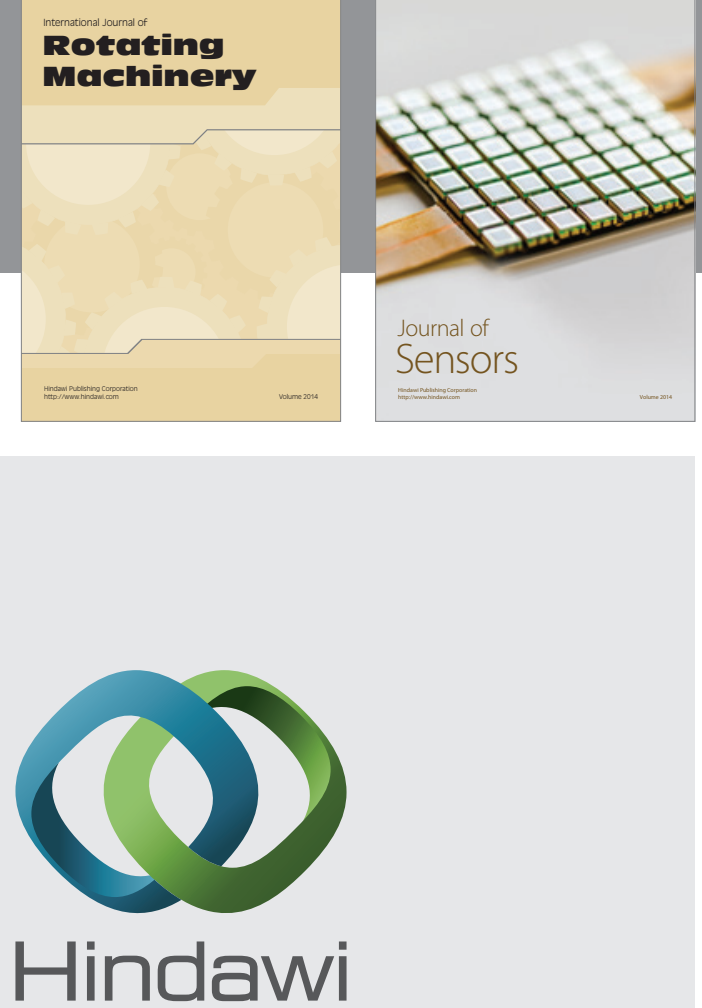

Submit your manuscripts at http://www.hindawi.com
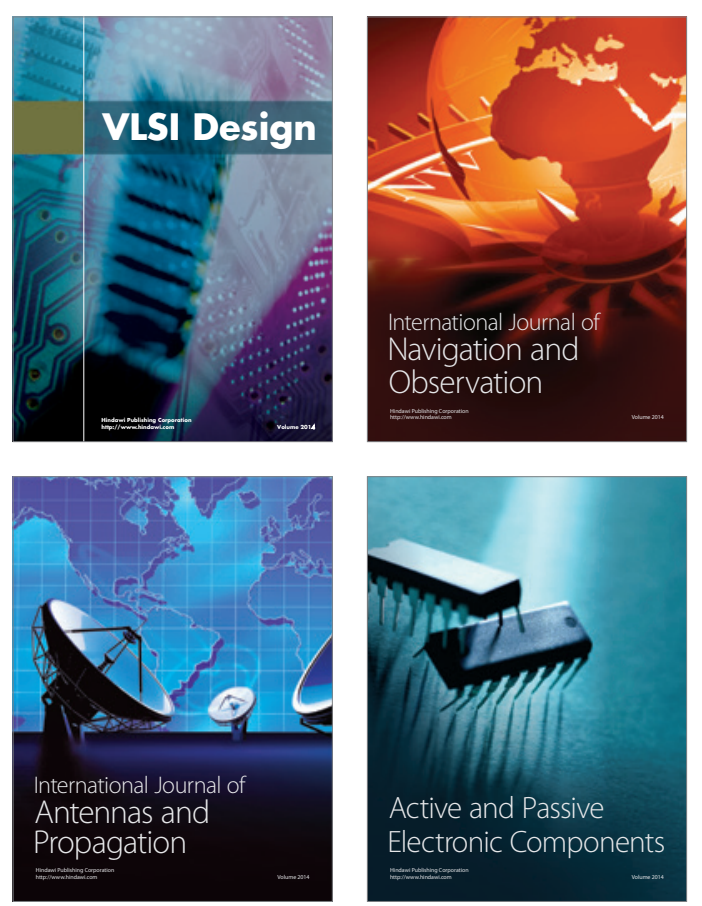
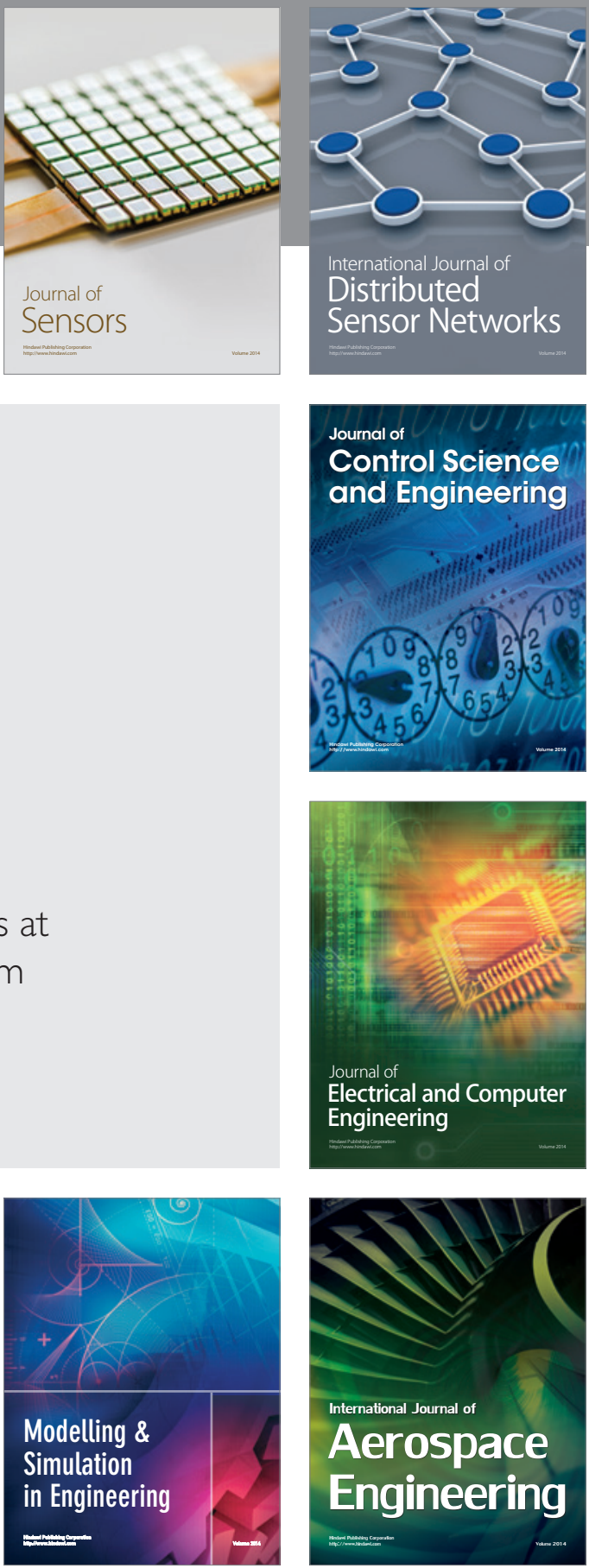

Journal of

Control Science

and Engineering
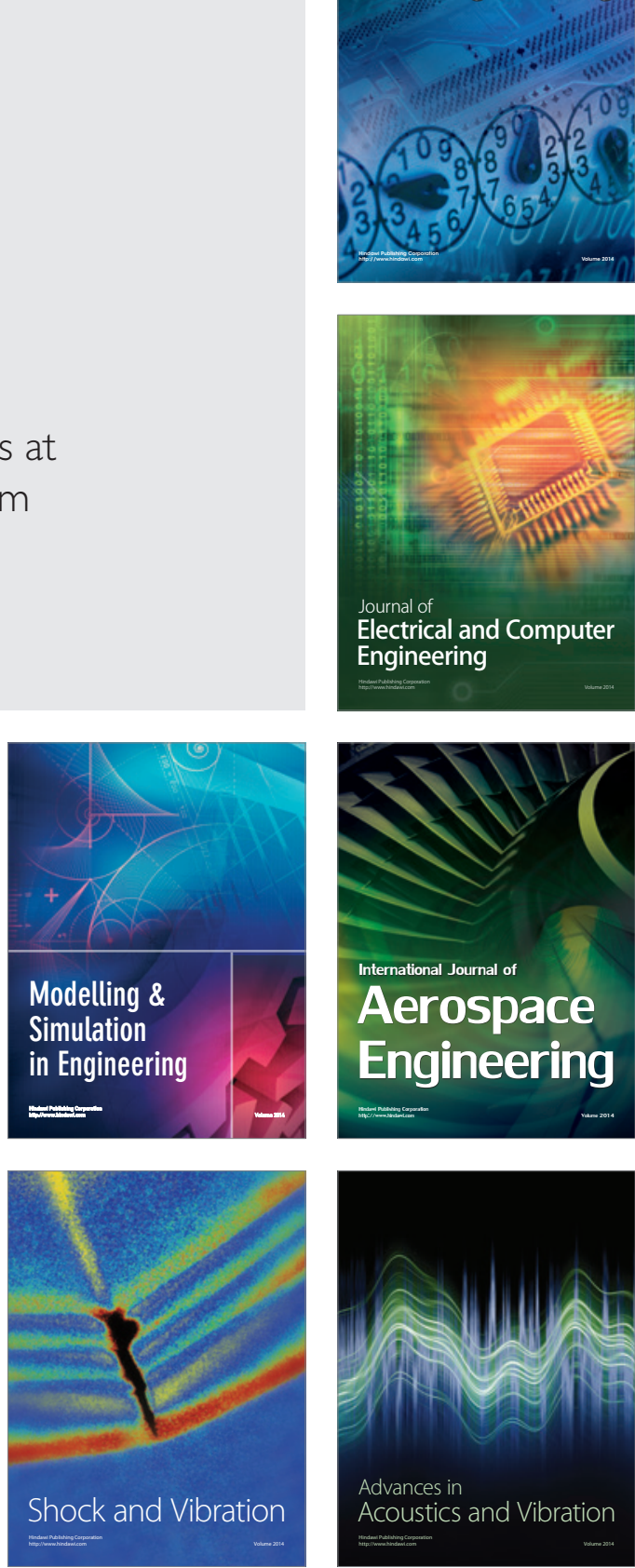